\title{
Experimental study for the effect of dust cleaning on the performance of grid-tied photovoltaic solar systems
}

\author{
Naseer K. Kasim ${ }^{1}$, Nibras M. Obaid ${ }^{2}$, Hatim G. Abood ${ }^{3}$, Raed Abed Mahdi ${ }^{4}$, Ali Mohmood Humada \\ ${ }^{1,4}$ Training and Energy Research Office, Ministry of Electricity, Iraq \\ ${ }^{2}$ Renewable Energy Department, Ministry of Electricity, Iraq \\ ${ }^{3}$ Department of Electrical Power and Machines, College of Engineering, University of Diyala, Iraq \\ ${ }^{5}$ State Company of Electricity Production-Northern Region, Ministry of Electricity, Iraq
}

\section{Article Info}

Article history:

Received Apr 21, 2020

Revised Jun 18, 2020

Accepted Jul 31, 2020

\section{Keywords:}

Automatic-cleaning

Dust deposition

Iraqi environment

Photovoltaic systems

Solar irradiance

\begin{abstract}
One of the challenges facing investment in photovoltaic (PV) energy is the accumulation of dust on the surface of the PV panels due to frequent dust storms in many countries, including Iraq. Surface dust particles reduce solar irradiance which declining the electrical performance of the PV solar systems. Therefore, this paper proposes an experimental study to analyze and evaluate the power efficiency of a PV system installed in Baghdad city, Iraq. The performance of dusty solar PV array is compared with that of the clean array of the same PV system. The clean solar array is equipped with an automatic-sprayer cleaning system that is powered by the PV system. The automatic cleaning system utilized in the test system reduces human effort by cleaning the PV array using closed-cycle water with low energy consumption (less than $10 \mathrm{Wh}$ ). The PV array under test is part of a $15 \mathrm{~kW}$ grid-tied PV system. The experimental results show significant improvement in the performance parameters of efficiency, performance ratio, and the energy gain compared to the clean array. Furthermore, the experimental study contributes to a reduction in $\mathrm{CO}_{2}$ emission, which is substantial for the Iraqi environment that suffers from predominate fossil-fuel power plants.
\end{abstract}

This is an open access article under the CC BY-SA license.

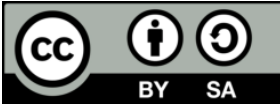

\section{Corresponding Author:}

Hatim G. Abood,

Department of Electrical Power and Machines,

College of Engineering, University of Diyala,

32001 Baqubah, Diyala Governorate, Iraq.

Email: hatim.abood@uodiyala.edu.iq

\section{INTRODUCTION}

Recently, power generation from solar photovoltaic (PV) power plants has grown drastically in response to energy demand and the environmental concerns related to $\mathrm{CO}_{2}$ emissions from fossil fuel consumption [1]. The sunny countries with large unpopulated areas such as countries in the Middle East, Northern Africa, the United States, India, and Australia are the favorite candidates to build vast solar PV systems $[2,3]$. Nevertheless, the environment in the solar-rich countries has a considerable rate of dust in the ambient air due to the barren lands and arid weather which substantially reduces the energy output of the solar PV systems $[4,5]$. In many cases, the refreshment of solar panels needs human efforts to remove the accumulated dust. Iraq is one of the most affected countries in the Middle East by the frequent sand storms which are clearly increased in the last decade due to desertification and climate change $[1,6,7]$. 
Many studies investigate the impact of soil and dust accumulation on the performance of PV systems in the Middle-East [3, 8, 9]. Atwan et al. [6] investigated the dust accumulation impact in Iraq environment conditions, the dust losses reached 66\% in April 2008 which has led to huge power losses. The authors [6] recommend cleaning of PV panels in Iraq as an essential condition to enhance the harvest of solar energy. Kasim et al. [8] implemented an experiment procedure in Baghdad city to evaluate the performance of fixed-tilt PV panels under natural dust accumulation compared to PV panels with a solar tracker system. The study [8] found that solar trackers contribute to removing dust and avoiding dust accumulation due to changing inclination. Other studies, such as [7], implemented simulation assessment using MATLAB to the performance of photovoltaic systems in Iraq.

In similar conditions to the Iraqi climate, [10] analyzes the performance of a $5.28 \mathrm{~kW}$ off-grid PV system in Saudi Arabia in 2012. The test system has sensors to detect the effect of PV surface temperature and dust collected on the PV panels for the study period of two months (July and August). The experimental study found that the daily energy was decreasing with days of accumulated dust on the panels surface and vice versa for the days with no dust. However, the study [10] was implemented on the off-grid PV system for only two summer months (July and August), and the performance evaluation concerns only DC performance ratios. Al-Housani et al. [11] presented the cleaning effectiveness on the cadmium-telluride technology performance in Doha, Qatar. The authors [11] identify enhancement of $6 \%$ in output power due to cleaning PV panels and they recommend weekly cleaning as the most efficient cleaning frequency compared to the daily and monthly cleaning. However, Moharram et al. [12] studied the impact of cleaning by water and surfactants on the performance of PV panels by removing dust deposits using less amount of water and energy. In the study [12], the influence of cleaning PV panels is tested using a non-pressurized water system on PV panels of a $14 \mathrm{~kW}$ solar system at the German University in Cairo, Egypt.

On the other hand, global studies such as that of Jaszczur et al. [13] studied the maximum dust deposition on PV systems in Poland, where the density observed for one week exceeds $300 \mathrm{mg} / \mathrm{m}^{2}$ in rainless weather and efficiency loss were about $2.1 \%$. The study found that efficiency loss depends on dust properties. Moreover, Jaszczur et al. [13] developed a reliable model for efficiency degradation of the PV modules caused by dust deposition. Likewise, Kawamoto and Shibata [14] investigated cleaning efficiency for six types of sand from different deserts using an electrostatic cleaning system. The study [14] states that more than $90 \%$ of the adhering sand is repelled from the surface of the slightly inclined panel after the cleaning operation. However, the performance of the system was further improved by enhancing the electrode configuration and introducing natural wind on the surface of the panel.

As the capital of Iraq, Baghdad is one of the most populated cities. Hence, the existing studies recommend a schedule cleaning for PV systems in Baghdad to avoid the pollutant particles that could deteriorate the PV modules when combined with the dust and humidity $[15,16]$. Therefore, this paper presented an experimental study for evaluating the effect of cleaning PV modules of $15 \mathrm{~kW}$ grid-tied PV system in Baghdad city. The study compares the DC and AC performance of two different PV arrays (clean and dusty) in the PV test system under various weather conditions for six months in 2019. The cleaning is implemented weekly using automatic Arduino-based water nozzles. The performance evaluation includes: energy outputs, modules yields, energy losses, PV system efficiency, and performance ratios.

\section{DESCRIPTION OF THE PV TEST SYSTEM}

The grid-tied PV system utilized in this study is installed in the Training and Energy Research Office subsidiary of the Iraqi Ministry of Electricity, Bagdad, Iraq. The geographical location of the test system is $44.4^{\circ} \mathrm{E}$ longitude, $33.3^{\circ} \mathrm{N}$ latitude, elevation $41 \mathrm{~m}$ above sea level (including the roof height), and the tilt angle is fixed at $30^{\circ}$ facing south with zero azimuth angle as shown in Figure 1 (see in appendix). The PV system is connected to the feeder that continuously provides electricity to the main building via smart meters. The PV system made up of 72 PV modules (Model: HIT-205DNKHE1) covering a total area of $83.57 \mathrm{~m}^{2}$ with a capacity of $15 \mathrm{~kW}$ as shown in Figure 2 (see in appendix). Each PV module provides a power of $205 \mathrm{Wp}$. The specifications of the PV modules are shown in Table 1 (see in appendix), further details can be found in $[17,18]$. The inverter used in the system is SMA Sunny Tripower, 15000TL-10 type [19]. This inverter has a rated maximum efficiency of $97 \%$ with a size of $15 \mathrm{~kW}$ and provided by monitoring system connected to Sunny portal program which offers daily, monthly, and yearly information of the power production. The size of dust particles recorded in Baghdad city is ranged from $(2-62 \mu \mathrm{m})$ for silica and $(0.5-2 \mu \mathrm{m})$ of clay particulates [16]. 


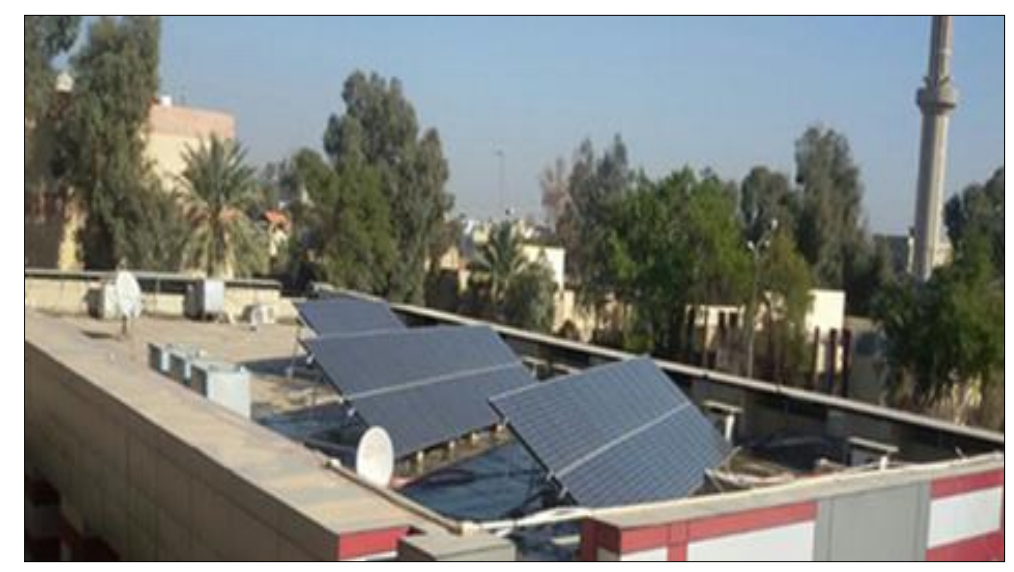

Figure 1. The grid-tied solar PV system of $15 \mathrm{~kW}$

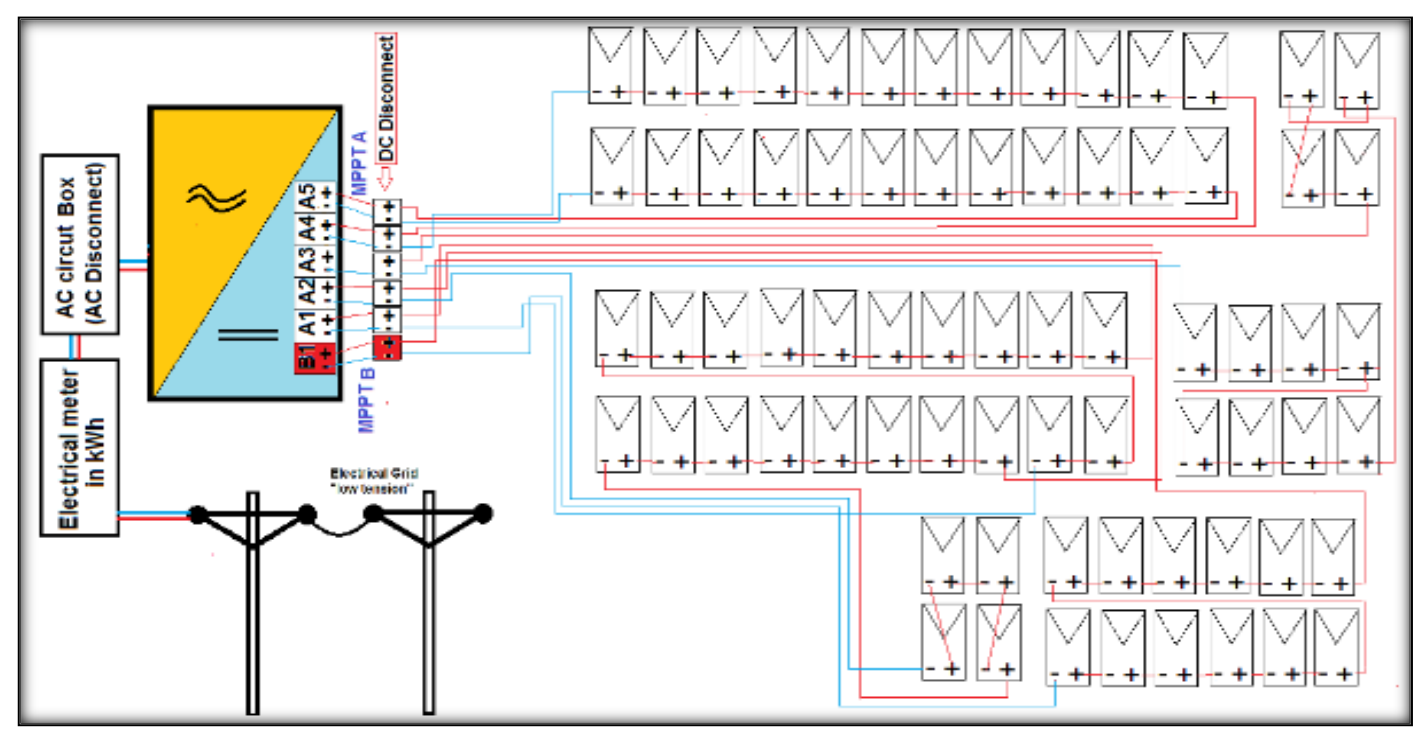

Figure 2. Schematic diagram of the pv solar grid-tied system

Table 1. The specifications of the test system PV modules [17]

\begin{tabular}{lc}
\hline \multicolumn{1}{c}{ Parameter } & Value/Description \\
\hline Cell type & HIT (Hitro Intrinsic Thin film) \\
Max. power (W) & 205 \\
Max. voltage (V) & 41.3 \\
Max. current (A) & 4.97 \\
Open circuit voltage (V) & 50.9 \\
Short circuit current (A) & 5.43 \\
Max. over current rating (A) & 15 \\
Power tolerance $(\%)$ & $+10 /-5$ \\
Max. system voltage (V) & 1000 \\
Temperature coeff. of Pmax $\left(\% /{ }^{\circ} \mathrm{C}\right)$ & -0.3 \\
Temperature coeff. of $\mathrm{Voc}\left(\mathrm{V} /{ }^{\circ} \mathrm{C}\right)$ & -0.127 \\
Temperature coeff. of Isc $\left(\mathrm{mA} /{ }^{\circ} \mathrm{C}\right)$ & 1.63 \\
Module Dimensions $(\mathrm{mm} \times \mathrm{mm})$ & $1630 \times 862$ \\
\hline
\end{tabular}

\section{ANALYSIS OF PERFORMANCE EVALUATION}

The parameters of performance evaluation of the grid-tied PV test system are energy output, efficiencies (array, system, and inverter efficiencies), yields (reference, array, and final yields), capacity factor, and the performance ratio $[18,20]$. 


\subsection{Energy output}

The total output of energy is defined as the AC power generated by the system in a given period of time. If $A C E$ refers to the alternating-current energy, the total hourly, daily, and monthly energy produced are respectively calculated by:

$$
\begin{aligned}
& A C_{-} E_{h}=\sum_{t=1}^{60} A C_{-} E_{t} \\
& A C_{-} E_{d}=\sum_{h=1}^{24} A C_{-} E_{h} \\
& A C_{-} E_{m}=\sum_{d=1}^{\mathrm{N}} A C_{-} E_{d}
\end{aligned}
$$

where $A C_{-} E_{t}$ is the production of energy (in a minute); $A C_{-} E_{h}$ is the production of energy (in an hour); $A C_{-} E_{d}$ is the production of energy in (day); $A C_{-} E_{m}$ is the production of energy (in a month), and $N$ represent days number of each month.

\subsection{System yields}

System yields include array yield $\left(Y_{A}\right)$, final $\left(Y_{F}\right)$ yield and reference yield $\left(Y_{R}\right)$. The array yield $\left(Y_{A}\right)$ is the DC energy product of PV array for an assumed duration per nominal PV power of the system. It refers to the time measured in $(\mathrm{kWh} / \mathrm{kWp})$ unit, and calculated as follows:

$$
Y_{A}=\frac{D C_{-} E}{P_{\text {rated }}}\left(k W h / k W_{P}\right)
$$

where $D C_{-} E$ is the DC energy product of the PV array in $(\mathrm{kWh})$ and $P_{\text {rated }}$ is the rated photovoltaic power.

The final yield $\left(Y_{F}\right)$ is the rate of AC energy product of the PV system over the assumed period of per system nominal/rated power [11]. The $Y_{F}$ is calculated in $\mathrm{kWh} / \mathrm{kWp}$ and it is given by:

$$
Y_{F}=\frac{A C_{-} E}{P_{\text {rated }}}\left(\mathrm{kWh} / \mathrm{kW}_{\mathrm{P}}\right)
$$

where $A C_{-} E$ is the $\mathrm{AC}$ energy output in $(\mathrm{kWh})$. The reference yield $Y_{R}$ is the global solar irradiation in collimated plane over the reference irradiance. The reference irradiance is calculated under standard conditions and its value of $1 \mathrm{kWp} / \mathrm{m}^{2}$. The reference yield is given by:

$$
Y_{R}=\frac{H_{T}}{H_{R}}\left(\mathrm{kWh} / \mathrm{kW}_{\mathrm{P}}\right)
$$

where $H_{R}$ refers to the reference irradiance and $H_{T}$ is the in-collimated solar irradiation.

\subsection{Energy losses of the array and system}

The losses of the array $\left(L_{A}\right)$ denote the losses because of the array act that exhibits the incapacity to entirely convert the irradiance to electricity [21]. The array capture losses are formulated as follows:

$$
L_{A}=Y_{R}-Y_{A}\left(\mathrm{kWh} / \mathrm{kW}_{\mathrm{P}}\right)
$$

System losses $\left(L_{S}\right)$ is due to the losses of DC to AC power conversion by the inverter of PV system.

$$
L_{S}=Y_{A}-Y_{F}\left(\mathrm{kWh} / \mathrm{kW}_{\mathrm{P}}\right)
$$

\subsection{System efficincies}

The efficiency of PV solar system is divided into three types: system, array, and inverter efficiency. These efficiencies are calculated periodically (annually, monthly, daily, hourly, and instantaneous). The system efficiency depends on AC power product, while the array efficiency depends on DC power product [21]. Array efficiency is given by:

$$
\eta_{P V}=\frac{100 * D C_{-} E}{H_{t} * A_{m}} \%
$$

where $A_{m}$ is the array area $\left(\mathrm{m}^{2}\right), H_{t}$ is the in-collimated plane solar irradiation. The system efficiency of PV solar system given by: 


$$
\eta_{S Y S}=\frac{100 * A C_{-} E}{H_{t} * A_{m}} \%
$$

The inverter efficiency is:

$$
\eta_{I N V}=\frac{100 * A C_{-} E}{E_{D C}} \%
$$

\subsection{Performance ratio}

Performance ratio $\left(P_{R}\right)$ is the ratio between final yields and the reference yield [11]. The $P_{R}$ values of any system shows how the PV solar system approaches to perfect performance through the actual act and permits comparison of PV systems regardless of angle, location, tilt, orientation and their nominal power capacity as shown in (12):

$$
P_{R}=\frac{Y_{F}}{Y_{r}} \%
$$

\subsection{Capacity factor}

The Capacity factor $\left(C_{F}\right)$ is a tool used to assess energy generated by an electric power generating system $[22,23]$. The $C_{F}$ is the ratio of AC energy generated by the PV solar system per a specified duration (usually one year) to the system energy if it works at whole capacity (rated value) for the same given period of time. The yearly $C_{F}$ of the PV system is as follows:

$$
C_{F}=\frac{A C_{-} E}{P_{P V, \text { rated }} * 8760}
$$

\section{EXPERIMENTAL TESTS}

\subsection{Cleaning system components}

The experimental setup is developed to investigate the impact of cleaning PV modules using sprayer water for power enhancement of the PV test system. The PV system contains 72 PV modules manufactured by Panasonic Company [17]. The automatic-cleaning system consists of the following main parts:

- Main Aluminum water tank ( $1 \mathrm{~m}^{3}$ capacity).

- Secondary water tank of $0.25 \mathrm{~m}^{3}$ capacity.

- Water pump of $1180 \mathrm{~W}$ (input power).

- Four water-nozzles for spraying water on the PV panels [24].

- A drain pipe for collecting the water.

- Automated unit to control the time of spraying water using a programmable Arduino kit.

The water pump absorbs water from the water tank by a suction pipe for avoiding any combined dust or dirt. As shown in the diagram of Figure 3, the sucked water is sprayed over the PV modules by the nozzles that are installed at the upper side of the PV panels. Next, the cleaning water is collected by a drain pipe at the lower part of the PV modules to flow in a closed cycle to the secondary tank. Finally, the secondary tank collects and feed the water to the main tank. The system also contributes to colling the PV panels in hot summer days and able to entilry remove the dust $[18,25]$.

\subsection{Experiment procedure}

The automated sprayer-water cleaning system with Arduino was running weekly for 30 minutes over six months. The cleaning starts in morning one day a week, at early-morning hours for decreasing water evaporation. The cleaning system pumps a reasonable amount of water to clean an area of $14 \mathrm{~m}^{2}$ with automatic control which dramatically reduces human effort and able to flush the dust particles (according to the statistics of the Iraqi environment [16]). Moreover, the low energy consumption, which is $9.8 \mathrm{Wh}$ for water-spraying system is powered by the solar PV system. Though Baghdad has its giant river, the closedwater system assists to save water which make the cleaning system feasible to barren and outback areas in western Iraq. Figure 4 displays an image of the proposed spray-water cleaning system.

The experiment applied on 24 modules divided to two PV arrays (12 modules each). The first PV array, left naturally without cleaning for the whole experiment period (except rain). Under the same weather conditions, solar radiation rate, and ambient temperature, the second PV array had been cleaning periodically using pressurized water. The effect investigates the cleaning influence and compares the enhancement energy and performance parameter with reference PV array (the dusty array). The measurements have been collected for six-months and the energy calculations implemented to evaluate the effect of cleaning PV panels on energy performance of the tested PV system. 


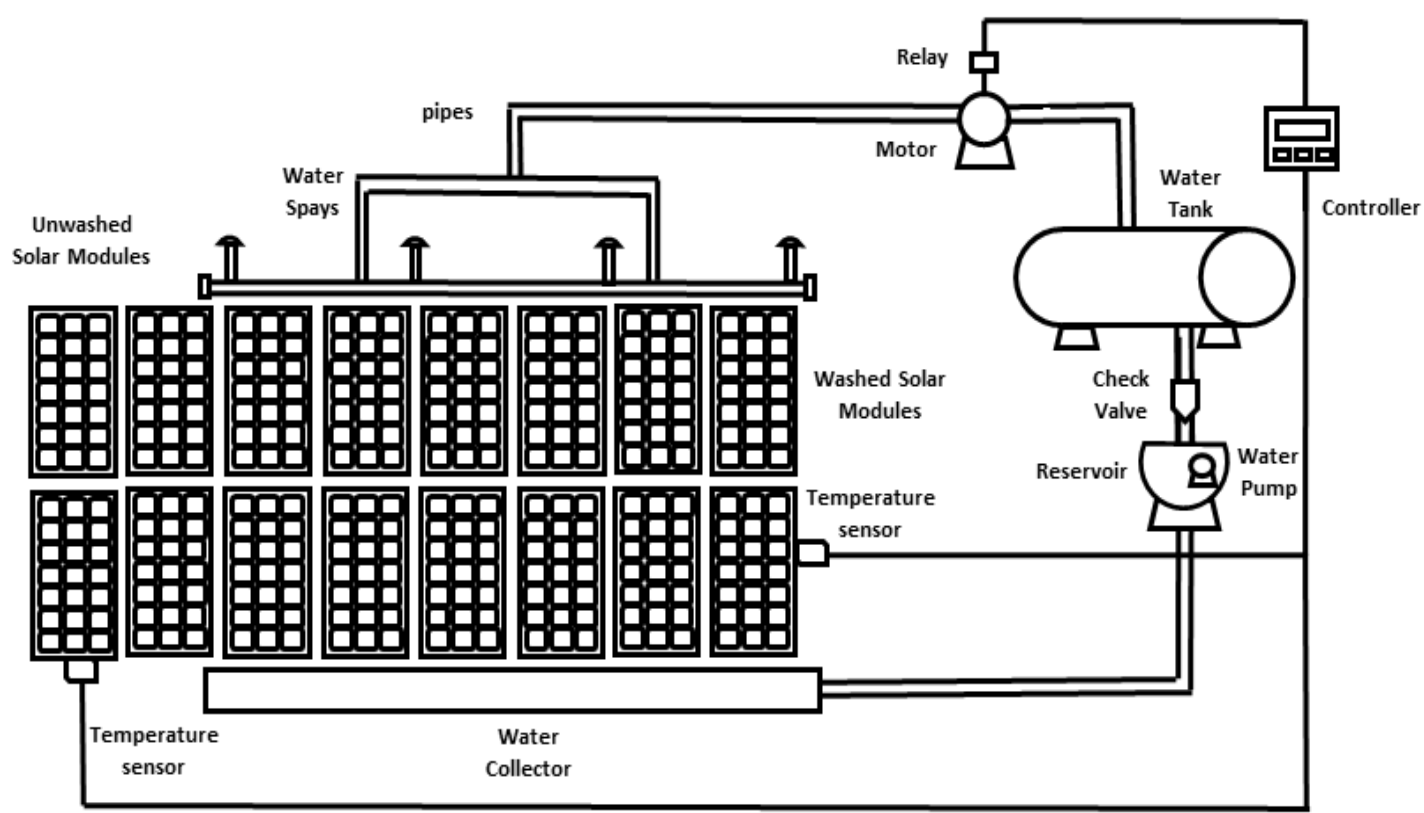

Figure 3. Schematic diagram of automated water-sprayer cleaning system

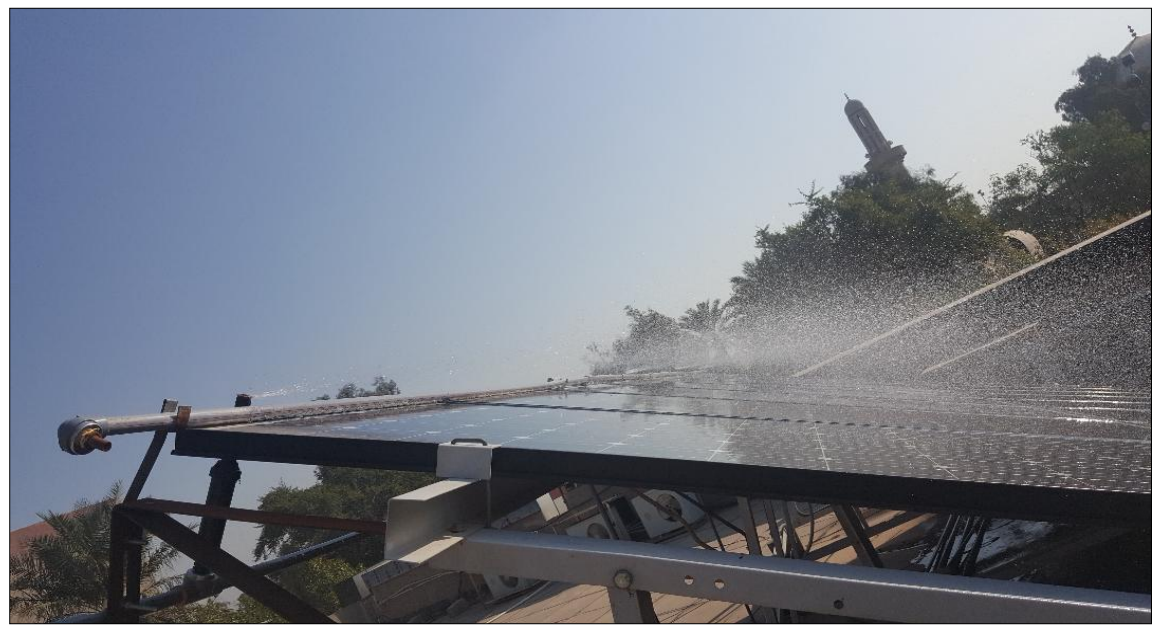

Figure 4. Working automatic-sprayer cleaning system

\section{RESULTS AND DISCUSSIONS}

The cleaning system of one array in the PV system of $15 \mathrm{~kW}$ had been running for six months in 2019 to analyze the impact of dust deposit and hence, the influence of cleaning the PV modules on the energy performance of its PV modules. The measurements have been daily recorded, and the relevant calculations implemented as described in section 3. Table 2 summarized the percentage energy gain of the two arrays of $15 \mathrm{~kW}$ solar PV system for the study period with the description of weather conditions. The percentage energy gain is calculated as the rate of energy differences (between the clean PV array and the reference array) to the energy of the reference PV array. The average energy gain is that of the four days in each month.

Based on Table 2, the average energy gain is obtained from the percentage energy gain of four days in each month included in the study. Figure 5 indicates that the maximum energy gain was in January with an average energy of $7.69 \%$ due to dust accumulation and a dust storm. Whereas, the minimum energy gain occurred in March and April by average values of $2.68 \%$ and $2.87 \%$ respectively because of the frequent rain showers that reduces the accumulated dust on the reference solar array. 
Table 2. The weather status and the percentage energy gain of the test system

\begin{tabular}{|c|c|c|c|c|}
\hline Day-Month & $\begin{array}{l}\text { Reference array energy } \\
(\mathrm{kW})\end{array}$ & $\begin{array}{c}\text { Clean array energy } \\
(\mathrm{kW})\end{array}$ & $\begin{array}{c}\text { Energy Gain } \\
(\%)\end{array}$ & Weather Status \\
\hline 7 Jan. & 7.614 & 7.947 & 4.363 & Dust accumulation \\
\hline 14 Jan. & 10.392 & 11.373 & 9.435 & Dust storm \\
\hline 21 Jan. & 7.529 & 8.447 & 12.19 & Dust accumulation \\
\hline 28 Jan. & 9.763 & 10.228 & 4.76 & Heavy Rainfall \\
\hline 7 Feb. & 10.801 & 11.277 & 5.99 & Dust accumulation \\
\hline 14 Feb. & 9.975 & 10.491 & 8.71 & Dust accumulation \\
\hline 21 Feb. & 8.061 & 8.222 & 4.098 & Rain shower \\
\hline 28 Feb. & 11.803 & 11.949 & 2.83 & Rain shower \\
\hline 7 Mar. & 8.457 & 8.612 & 3.45 & Dust accumulation \\
\hline 14 Mar. & 8.230 & 8.340 & 2.82 & Rain shower \\
\hline 21 Mar. & 7.710 & 7.780 & 1.86 & Heavy Rainfall \\
\hline 28 Mar. & 1.753 & 1.770 & 2.61 & Rain shower \\
\hline 7 Apr. & 8.601 & 8.801 & 3.23 & Rain showers \\
\hline 14 Apr. & 7.347 & 7.431 & 2.10 & Rain showers \\
\hline 21 Apr. & 10.901 & 11.210 & 3.89 & Dust accumulation \\
\hline 28 Apr. & 10.885 & 10.999 & 2.28 & Rain full \\
\hline 7 May & 8.268 & 8.633 & 5.367 & Dust accumulation \\
\hline 14 May & 8.341 & 8.816 & 6.602 & Dust accumulation \\
\hline 21 May & 7.954 & 8.353 & 5.868 & Wind (9-14) km/h \\
\hline 28 May & 8.115 & 8.523 & 5.76 & Wind $(5-14) \mathrm{km} / \mathrm{h}$ \\
\hline 6 Jun. & 7.143 & 7.447 & 6.07 & Dust accumulation \\
\hline 13 Jun. & 9.385 & 9.792 & 5.17 & Wind (6-15) km/h \\
\hline 20 Jun. & 9.414 & 9.791 & 4.87 & Wind (4-11) km/h \\
\hline 27 Jun. & 9.789 & 10.622 & 9.26 & Dust storm and wind \\
\hline
\end{tabular}

From Figure 5, the energy output $\Delta E$ increased from 0.25 to $2.75 \mathrm{kWh} /$ day for one array. Thus, the average energy enhancement ranges from $2.68 \%$ to $7.69 \%$ of energy output of the reference array. The energy produced by the clean and reference arrays and the energy difference due to the cleaning process are shown in Figure 6. It can be noticed that winter months in Iraq (January and February) approximately yields the same energy gain of dry months (May and June). The evident reason is the accumulated dust due to arid weather and no rainfall. Frequent active wind and low humidity of summer months in Iraq had played a significant role in reducing dust accumulation on the surface of PV modules by decreasing adhesion force of dust particles on modules surface.

As the dust accumulation negatively affects the conversion efficiency in solar PV by blocking the solar radiation to reach the solar modules. Hence, the efficiency of the PV system increased due to the cleaning process. Figure 7 shows the average efficiency difference for six months of the experiment. It was found that the maximum array efficiency rises in January with a value of $1.31 \%$. Whereas, minimum efficiency value obtained in months of spring season with values of $0.09 \%$ and $0.11 \%$ for March and April, respectively.

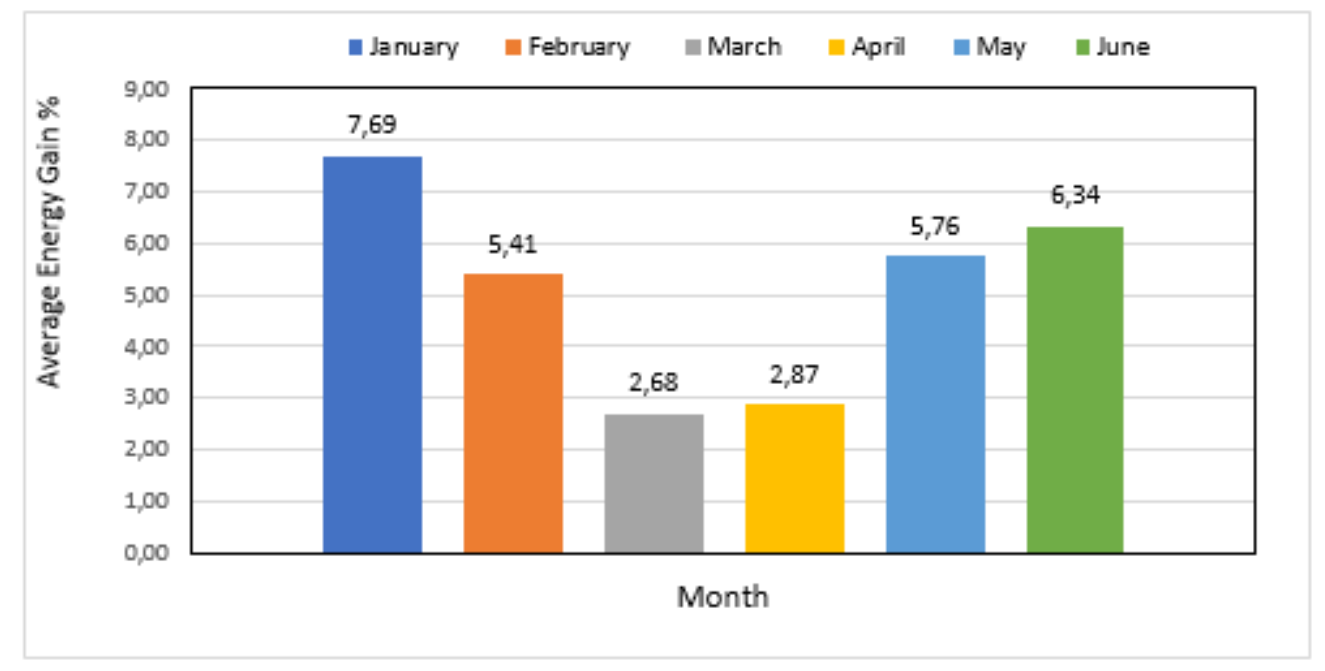

Figure 5. Working average energy gain (in percentages) of six months 


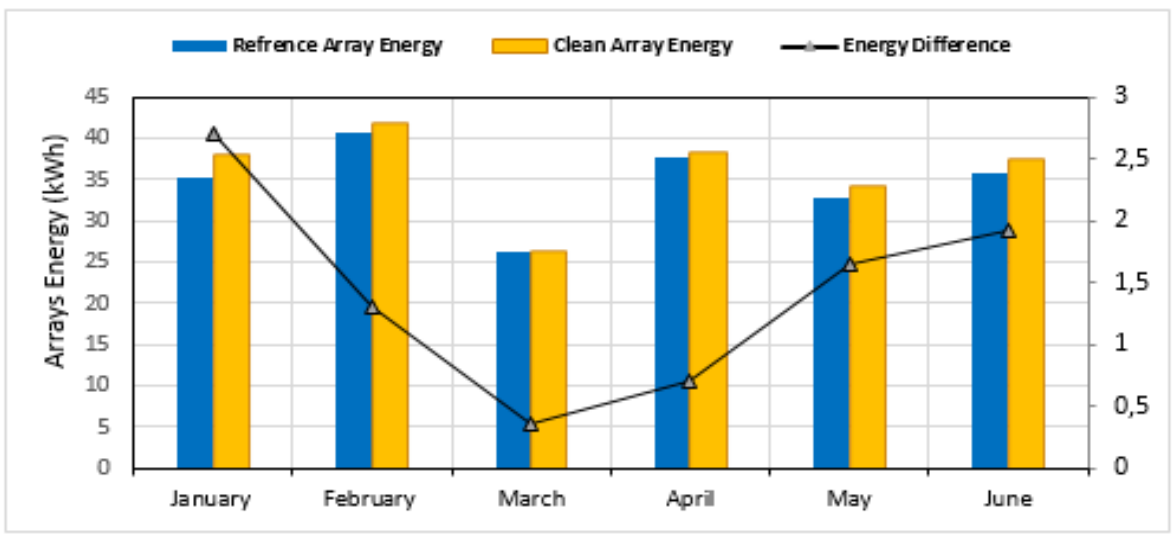

Figure 6. Energy output of clean and reference arrays

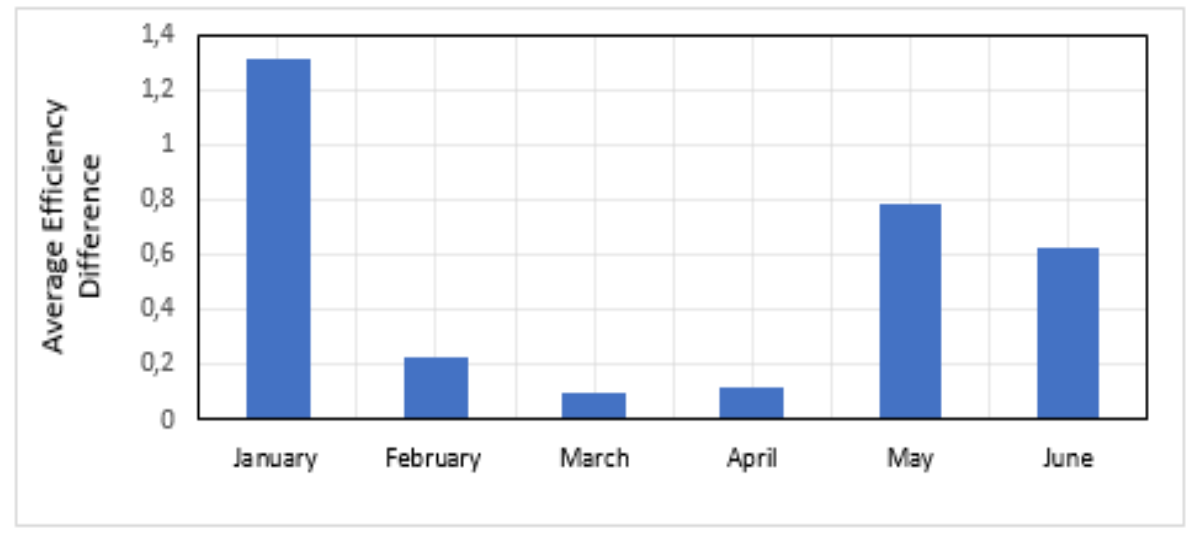

Figure 7. Average efficiency difference in evaluated arrays for six months

The improvement in PV efficiency is accompanied with decreasing losses that positively influenced an important parameter, which is performance ratio $\left(P_{R}\right)$. Performance ratio represents the percentage of energy produced from rated energy. The maximum average $P_{R}$ difference was recorded in January with value of $4.34 \%$. Whereas, the obtained value in June was $3.39 \%$ as shown in Figure 8. Although arid weather in summer months, the performance values remained relatively high due to active wind and low humidity which led to easy removal of the accumulated dust. However, minimum values were obtained during spring season with values of $0.53 \%$ and $0.65 \%$ in March and April, respectively.

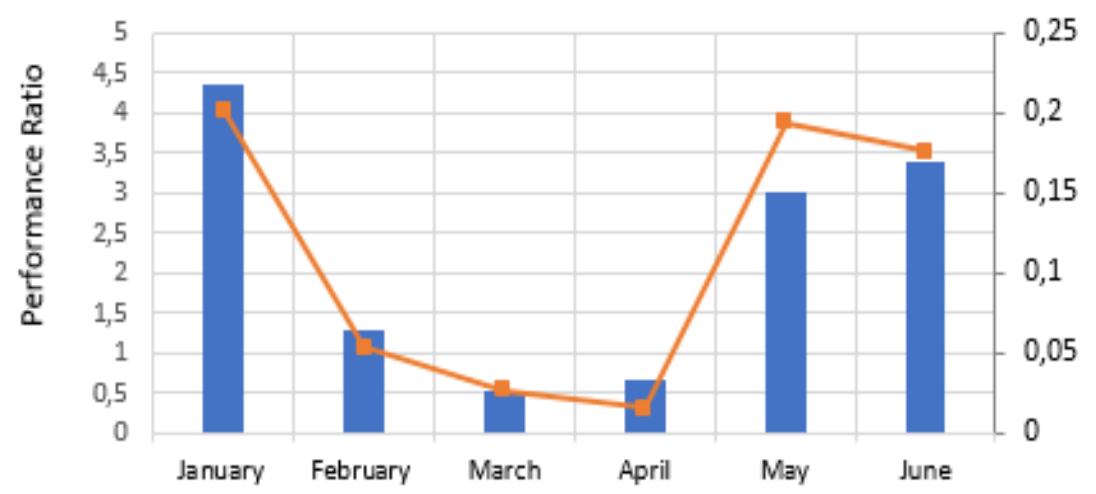

Figure 8. Average performance ratio difference and the losses in the evaluated array 
The array yield and final yield indicate the hours number that the PV solar system can generate DC and $\mathrm{AC}$ power in its nominated capacity. Figure 9 demonstrates the array and final yields difference between two of clean and dirty PV arrays for six months. The measurements showed that maximum yields were in January due to the dust storm, and minimum yields happened in March, because of the rain showers that led to the natural cleaning for the two arrays.

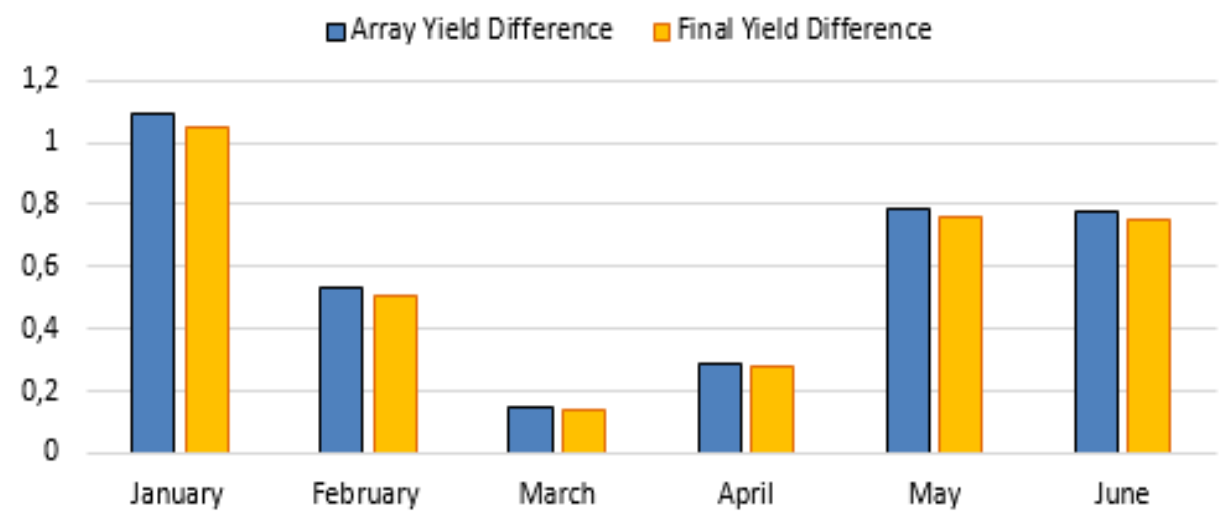

Figure 9. Average array and final yields difference in evaluated arrays

On the other hand, the main reason beyond utilizing solar power plants is for producing clean energy and reducing carbon emission. Hence, increasing output energy is accompanied with reduction in pollution. Figure 10 shows reduction in $\mathrm{CO}_{2}$ level for six months of the experimental study. The avoidable $\mathrm{CO}_{2}$ is ranged between $(1.88-0.24) \mathrm{kg} /$ day and increased at the same level of energy output improvement.

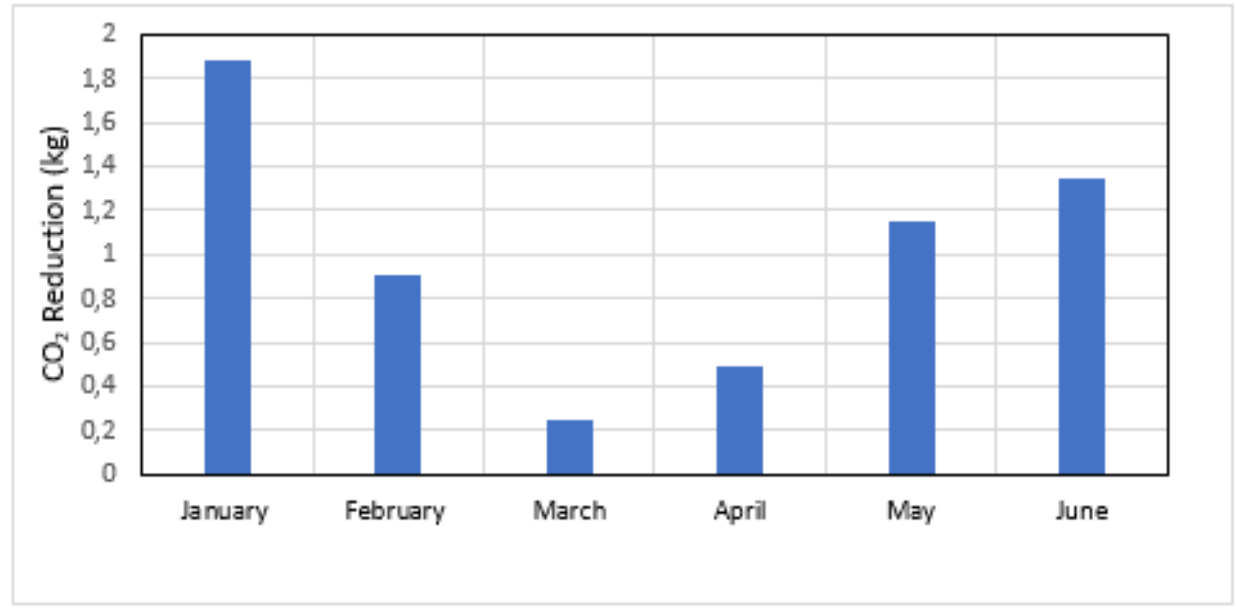

Figure 10. Reduction in $\mathrm{CO}_{2}$ over the experiment period

\section{CONCLUSION}

Cleaning solar power systems from dust and dirt deposition is necessary to maintain the power output of PV modules. The cleaning system proposed in this study enhances the parameters of efficiency, performance ratio, and the average energy gain by $4.34 \%, 1.31 \%$ and $7.69 \%$ respectively using an energyefficient automatic the water-spray system. According to the standard of the Iraqi environment, the experimental study included months belongs to three different seasons (winter, spring, and summer) which covered rainy, dusty and dry weather conditions. The low energy of water-pump motor is provided by PV system itself. Results show promising improvements in performance parameters of array yield, final yield, efficiencies and performance ratio, as well as the cleaning, has an effect on boosting modules life by 
preventing hot spot formation. Moreover, the results show a reduction in $\mathrm{CO}_{2}$ emission by $1.8 \mathrm{Kg} / \mathrm{day}$ which is promising to decline the pollution in Baghdad city. The improvement in the energy performance in addition to the reduction in $\mathrm{CO}_{2}$ emission should encourage utilities to adopt similar cleaning procedures.

\section{REFERENCES}

[1] R. Sadiq, H. Karunathilake, and K. Hewage, "Renewable energy selection for net-zero energy communities : Life cycle based decision making under uncertainty," Renewable energy, vol. 130, pp. 558-573, 2019.

[2] A. Z. Abass and D. A. Pavlyuchenko, "The exploitation of western and southern deserts in Iraq for the production of solar energy," International Journal of Electrical and Computer Engineering, vol. 9, no. 6, pp. 4617-4624, 2019.

[3] O. A. M. Omar, N. M. Badra, and M. A. Attia, "Enhancement of On-grid PV System under Irradiance and Temperature Variations Using New Optimized Adaptive Controller," International Journal of Electrical and Computer Engineering (IJECE), vol. 8, no. 5, pp. 2650-2660, 2018.

[4] B. Weber, A. Quiñones, R. Almanza, and M. D. Duran, "Performance Reduction of PV Systems by Dust Deposition," Energy Procedia, vol. 57, pp. 99-108, 2014.

[5] M. Mani and R. Pillai, "Impact of dust on solar photovoltaic (PV) performance: Research status, challenges and recommendations," Renewable and sustainable energy reviews, vol. 14, no. 9, pp. 3124-3131, 2010.

[6] A. F. Atwan, N. K. Kasim, and A. H. Shneishil, "PV solar panel performance under the effect of dust in Baghdad," Atti della Fondazione Giorgio Ronchi, Fondazione Giorgio Ronchi, pp. 379-388, 2012.

[7] A. H. Ali, H. S. Hamad, and A. A. Abdulrazzaq, "Performance Investigation of Grid Connected Photovoltaic System Modelling Based on MATLAB Simulation," International Journal of Electrical and Computer Engineering (IJECE), vol. 8, no. 6, pp.4847-4854, 2018.

[8] N. K. Kasim, et al., "Evaluating the performance of fixed solar panels relative to the tracking Solar Panels under natural deposition of dust," Baghdad Science Journal, vol. 7, no. 1, pp. 544-555, 2019.

[9] H. Rezk, I. Tyukhov, and A. Raupov, "Experimental implementation of meteorological data and photovoltaic solar radiation monitoring system," International Transactions on Electrical Energy Systems, vol. 25, no. 12, pp. 3573-3585, 2015.

[10] S. Rehman and I. El-amin, "Performance evaluation of an off-grid photovoltaic system in Saudi Arabia," Energy, vol. 46, no. 1, pp. 451-458, 2012.

[11] M. Al-housani and Y. Bicer, "Assessment of Various Dry Photovoltaic Cleaning Techniques and Frequencies on the Power Output of CdTe-Type Modules in Dusty Environments," Sustain. Artic., vol. 11, no. 10, pp. 1-18, 2019.

[12] K. Moharram, M. Abd-Elhady, H. Kandil, and H. El-Sherif, "Influence of cleaning using water and surfactants on the performance of photovoltaic panels," Energy Convers. Manag., vol. 68, pp. 266-272, 2013.

[13] M. Jaszczur et al., "The field experiments and model of the natural dust deposition effects on photovoltaic module efficiency," Environ. Sci. Pollut. Res., vol. 26, no. 9, pp. 8402-8417, 2019.

[14] H. Kawamoto and S. Takuya, "Electrostatic cleaning system for removal of sand from solar panels," J. Electrostat., vol. 73, pp. 65-70, 2015.

[15] M. A. Al-Nimr and W. A. M. Al-Shohani, "Performance of photovoltaic module for different sites in Iraq," Arab. J. Sci. Eng., vol. 38, no. 2, pp. 277-283, 2013.

[16] K. A. Kadhum and M. A. Rasheed, "Some Characteristics of Sand and Dust Storm Sources in Iraq," 2nd International Conference for Engineering, Technology and Sciences of Al-Kitab (ICETS), pp. 11-15, 2018.

[17] SANYO Component Europe GMBH, "HIT Double Photovoltaic module," SANYO. [Online]. Available: https://zonnepanelen.net/nl/pdf/panels/SANYO_HIT-210_205_200_DNKHE1_EN_.pdf.

[18] J. C. Ogbulezie, "The impact of high temperature and irradiance source on the efficiency of polycrystalline photovoltaic panel in a controlled environment," International Journal of Electrical and Computer Engineering (IJECE), vol. 10, no. 4, pp. 3942-3947, 2020.

[19] SMA SunnyTripower, "Sunny Tripower 15000Tl / 20000Tl / 25000Tl," 2019. [Online]. Available: https://files.sma.de/d1/24336/STP25000TL-30-DES1742-V31web.pdf.

[20] M. Saidan, A. Ghani, E. Alasis, and J. K. Kaldellis, "Experimental study on the effect of dust deposition on solar photovoltaic panels in desert environment," Renew. Energy, vol. 92, pp. 499-505, 2016.

[21] A. Y. Al-Hasan, "A New Correlation for Direct Beam Solar Radiation Received by Photovoltaic Panel with Sand Dust Accumulated on Its Surface," Sol. Energy, vol. 63, no. 5, pp. 323-333, 1998.

[22] N. M. Obaid, N. K. Kasim, and E. T. Hashim, "Performance Assessment of First Grid-tied PV Solar System under Baghdad City Climate Condition," Iraqi J. Sci. Technol., vol. 10, no. 1, pp. 63-71, 2019.

[23] N. K. Kasim, H. H. Hussain, and A. N. Abed, "Performance Analysis of Grid-Connected CIGS PV Solar System and Comparison with PVsyst Simulation Program,” Int. J. SMART GRID, vol. 3, no. 4, pp. 1-8, 2019.

[24] "Rain Bird 12Van Nozzle Only 12'," amazon, 2020. [Online]. Available: https://saudi.souq.com/sa-en/rain-bird12van-nozzle-only-12-33324033/i/\#description.

[25] N. S. B. Rukman, A. Fudholi, I. Taslim, M. A. Indrianti, and I. N. Manyoe, "Overview on recent photovoltaic module cooling methods: Advances PVT systems," International Journal of Electrical and Computer Engineering (IJECE), vol. 10, no. 1, pp. 15-21, 2020. 